\title{
Reverse engineering of B-pillar with 3D optical scanning for manufacturing of non-uniform thickness part
}

\author{
Md. Tasbirul Islam ${ }^{1}$, A.B. Abdullah ${ }^{1, *}$, and Mohamad Zihad Mahmud ${ }^{2}$ \\ ${ }^{1}$ School of Mechanical Engineering, Universiti Sains Malaysia (USM), Engineering campus, 14300 \\ Nibong Tebal Penang, Malaysia \\ ${ }^{2}$ School of Aerospace Engineering, Universiti Sains Malaysia (USM), Engineering campus, 14300 \\ Nibong Tebal, Penang, Malaysia
}

\begin{abstract}
This paper presents reverse engineering (RE) of a complex automobile structural part, B-pillar. As a major part of the automobile body-in white (BiW), B-pillar has substantial opportunity for weight reduction by introducing variable thickness across its sections. To leverage such potential, an existing B-pillar was reverse engineered with a 3D optical scanner and computer aided design (CAD) application. First, digital data (i.e. in meshes) of exiting B-pillar was obtained by the scanner, and subsequently, this information was utilized in developing a complete 3D CAD model. CATIA V5 was used in the modeling where some of the essential work benches were 'Digitized Shape Editor', 'QQuick Surface Reconstruction", 'Wireframe and Surface Design", "Freestyle", "Generation Shape Design" and "Part design". In the final CAD design, five different thicknesses were incorporated successfully in order to get a B-pillar with non-uniform sections. This research opened opportunities for thickness optimization and mold tooling design in real time manufacturing.
\end{abstract}

\section{Introduction}

Major automotive manufacturers have been working to produce lightweight vehicles in order to adhere with continuous strict regulations that demand for less greenhouse gas emission and increased fuel efficiency [1]. Among various systems of a vehicle, body-inwhite $(\mathrm{BiW})$ is found as the most significant portion representing about $30 \%$ of the weight of a vehicle, and has tremendous potential in reducing weight of the whole vehicle [2]. Figure 1 shows the breakdown of vehicle weight by systems and components. As BiW possesses such opportunity, and has high sensitivity to structural integrity, it is the only system that is researched, designed and analyzed extensively in the studies of weight reduction technology for automobile [3]. Important components in the BiW system are passenger compartment frame, cross and side beams, roof structure, front-end structure, underbody floor structure and panels [4].

\footnotetext{
* Corresponding author: mebaha@usm.my
} 


\begin{tabular}{|c|c|c|c|}
\hline $\begin{array}{r}\text { Approximate } \\
\text { mass break }\end{array}$ & $\begin{array}{l}\text { vehicle } \\
\text { down }\end{array}$ & System & Major components in system \\
\hline \multirow{2}{*}{$\begin{array}{l}\text { Misc;; } \\
\text { Closures, } 7-8 \% \\
\text { fenders; } \\
8 \%\end{array}$} & \multirow[b]{2}{*}{$\begin{array}{l}\text { Body; } \\
23-28 \%\end{array}$} & Body-in-white & $\begin{array}{l}\text { Passenger compartment frame, cross and side beams, roof } \\
\text { structure, front-end structure, underbody floor structure, panels }\end{array}$ \\
\hline & & Powertrain & Engine, transmission, exhaust system, fuel tank \\
\hline \multirow[t]{4}{*}{$\begin{array}{l}\text { Interior; } \\
10-15 \%\end{array}$} & \multirow{4}{*}{$\begin{array}{l}\text { Powertrain; } \\
2428 \%\end{array}$} & Chassis & Chassis, suspension, tires, wheels, steering, brakes \\
\hline & & Interior & Seats, instrument panel, insulation, trim, airbags \\
\hline & & Closures & Front and rear doors, hood, lift gate \\
\hline & & Miscellaneous & Electrical, lighting, thermal, windows, glazing \\
\hline
\end{tabular}

Fig. 1. Breakdown of vehicle weight by system and components (adopted from [3]).

BiW is mostly consists of thin-walled structural parts, which are constructed either by stamping or forming process of traditional metal sheets with uniform thickness [5]. On the other hand, non-uniform thickness section is found as one of the most effective approaches to reduce automotive part weight [6]. The most complex of all structures in a vehicle, Bpillar is located between the front and rear doors of compartment in the BiW system. Generally, it covers the electrical wiring and connections and spots for the passenger seatbelts. It also provides structural support against lateral or roof impact [2]. Figure 2 shows the B-pillar in a passenger car. For side impact safety, B-pillar is a major structural component in the BiW [7]. Having these two folded characteristics (i.e. firstly as being part of the BiW that has weight reduction opportunity, and secondly, critical to vehicle's structural integrity), the optimum design of the B-pillar must be maintain; which made the B-pillar as one of the important components in BiW system with increasing interest for further development.

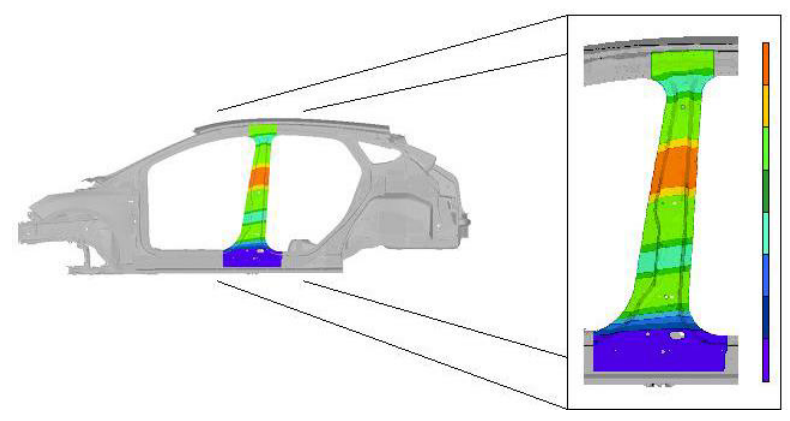

Fig. 2. B-pillar part in a typical passenger car (adopted from [8]).

Besides, traditional material alternatives and optimization techniques, manufacturing process of B-pillar is now being involved with some promising approaches such as tailor rolled blanks (TRBs) and tailor welded blanks (TWBs), where different sections of a Bpillar have non-uniform thickness, aiming to have reduced weight [8]. It is to be mentioned that TWB is an advanced manufacturing technology that consists of sheet metals that are laser welded and are characterized by different thickness and material within a single work piece [9]. On the other hand, in TRB, with a flexible rolling operation, continuous thickness transition can be made between thick and thin of a sheet metal. The thickness variation is obtained by adjusting roll gap. Research conducted by Hyrcza-Michalska et al. (2010) [10] found that using TWB for B-pillar, weight reduction was possible by $16 \%$ compared to conventional uniform thickness of the part. On the other hand, when TRB technology is employed, it was found that weight reduction of $2 \mathrm{~kg} /$ side was possible that consists of five 
different thicknesses in the B-pillar of a new BMW X5 car [11]. Another research by [8] found that weight of a B-pillar made by TRB technology with eight different thicknesses reached just over $7 \mathrm{~kg}$; a total weight saving of $1.3 \mathrm{~kg}$ when it is compared to conventional B-pillar design with uniform thickness. It is clear that thickness variation in different BiW system, particularly in B-pillar can significantly contribute to overall weight reduction of a vehicle.

Despite having such competitive advantages, these technologies have to follow two step processes where substantial effort and time is required to manufacture the part [12]. For instance, TRB infused B-pillar manufacturing; firstly, the TRBs are made up with the rolling process by controlling roll gap thus creating the varying thickness. After that direct hot stamping and rapid cooling is done on the TRBs, followed by laser and tool trimming for the final part. Therefore, to reduce the manufacturing time and effort, it is proposed in this research that development of a B-pillar can be made through a single process by cold forming operation where non-uniform thicknesses of the B-pillar sections will be incorporated in the tooling design of the forming operation. It is assumed to minimize the efforts of the subsequent manufacturing processes. However, to implement such idea, at first, a B-pillar with uniform thickness should be considered as a experimental object and then a reverse engineering (RE) process can be done. In this way, the actual physical object is transferred to a computer aided design (CAD) system, and further design modification can be made in order to achieve weight reduction compared with the existing one. The final modified B-pillar part will have variable thicknesses across its sections.

$\mathrm{RE}$ is the branch of engineering which takes advantage of an object that has already been created. The final purpose of RE is to create similar kind of identical object to the existing object considering rapid prototyping concept [13]. However, one of the essential prerequisite of this process is to get information about the physical nature of the object. In all areas in rapid prototyping, such as software, electronic components, automobile components, RE is widely being used for shorter product development time with optimized cost of the product [14]. The method is widely used and it consists a number of steps starting from capturing virtual model with a 3D optical scanner to 3D model development in CAD software [14]. The scanner coverts the physical object into point could or meshes. This kind of reverse engineering is generally being employed where access of such recorded $3 \mathrm{D}$ objects are confidential and identified as potential patent infringement [15]. Considering this as an important fact and to deploy rapid prototyping, RE process of the Bpillar outer part is presented in this research. This paper is organized in the following sections,

- Section 2 describes the experimental setup where the information of the physical object was transferred to meshes by 3D optical scanning,

- Section 3 highlighted the result and discussion of the research and finally,

- Section 4 concludes with achievement, limitations and future work.

\section{Experimental setup}

\subsection{Scanning of B-pillar part}

The B-pillar used in this research had complicated geometry and some free flowing surfaces. Due to relatively large size of B-pillar part, the scanning of the part was conducted in three different projections and then aligned for the complete mesh. The part had to provide with alignment points which were situated strategically for ensuring correct mesh. The original part was painted with a black colour developer spray to avoid any reflection during scanning. In this manner, the right meshes were found. The scanning of the part was 
conducted with the NEXTENGINE 3D optical high definition scanner that is installed in the fabrication lab at Universiti Sains Malaysia, Engineering campus. Figure 3 shows the flowchart of the process from original part to the mesh acquisition. The scan was performed in the dark space which was a prerequisite environment to avoid damages on the mesh. Finally, the meshes were found and oriented for three different faces using scanning software.
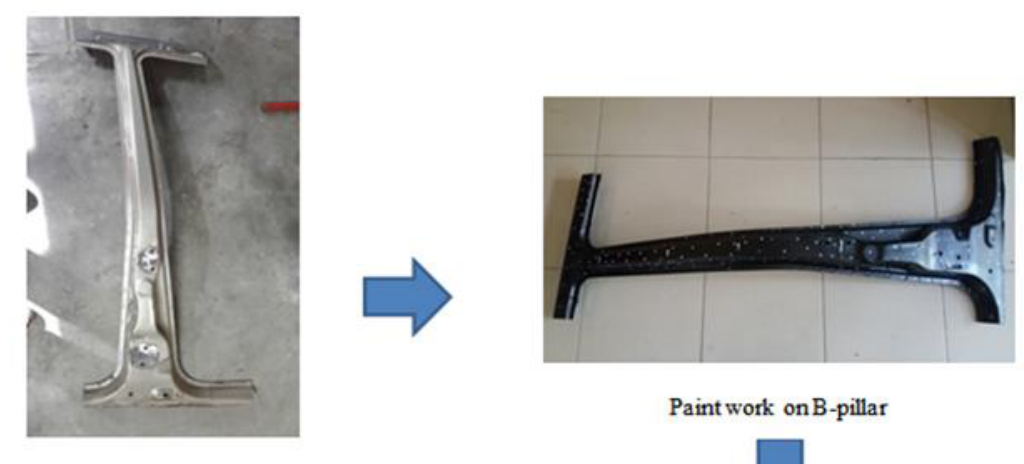

Experim entalB-pillar
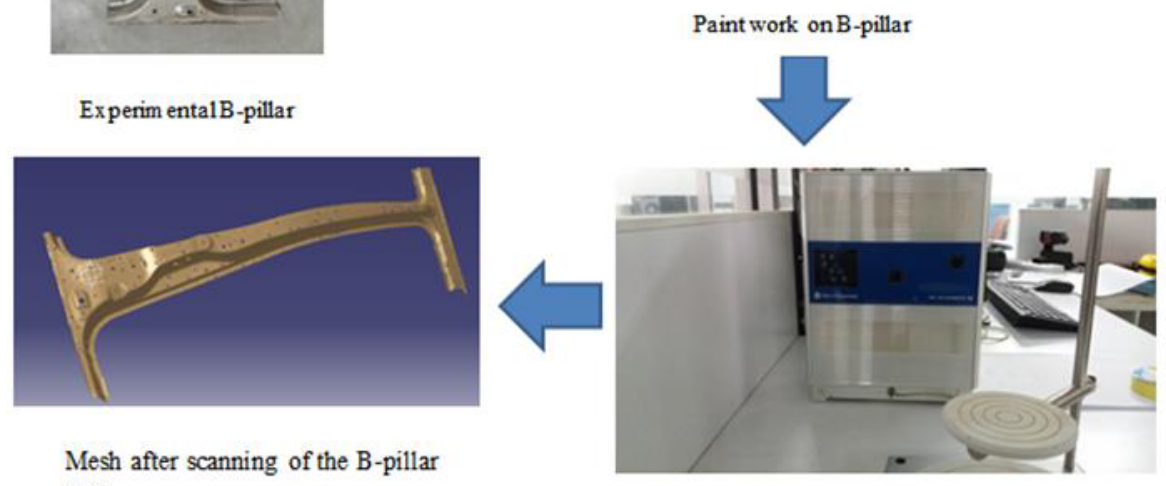

Mesh after scanning of the B-pillar part

NEXIENGINE optica13D

Fig. 3. Flowchart of mesh acquisition using $3 \mathrm{D}$ optical scanner.

\section{Results and discussion}

\subsection{Mesh repair}

After 3D scanning, the scanner software generated a (.STL) file extension that consists of meshes of the B-pillar. Initially, the obtained mesh had discontinuity, and large holes. The holes in the mesh were repaired with the fill holes, mesh smoothing, and mesh cleaning command under the 'Digitized Shape Editor'' workbench in the CATIA V5. Figure 4 shows the repaired mesh. Finally, the repaired meshes were used for developing a solid CAD model. Generally, the mesh provided a guide for placing lines and surfaces, and at the end of the process, final structure of the part will be similar to the mesh. 


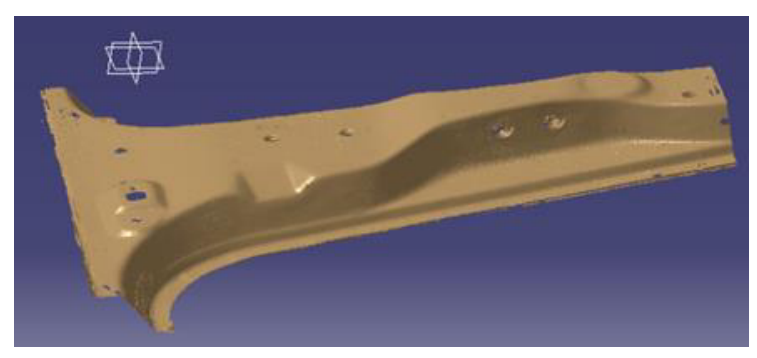

Fig. 4. Repaired mesh in Catia V5.

\subsection{Reverse engineering of the surfaces}

RE was started in the part by creating surfaces that exactly matched with the mesh. To create the surfaces, two important workbenches were utilized namely as "Quick Surface Reconstruction"' and 'Wireframe and Surface Design'. The surfaces were generally identified by placing $3 \mathrm{D}$ curves on the mesh, and by selecting the surface activate command. As the part contained a number of different surfaces, this process was performed repeatedly until the acceptable surfaces were created. This was valid for the surfaces which have relatively free flowing shape. On the other hand, the meshes which are comparatively straight in nature and did not have complex shape were constructed by tools located at the "'Generative shape design"' workbench. Figure 5 shows the surface creation using the mesh and workbenches.

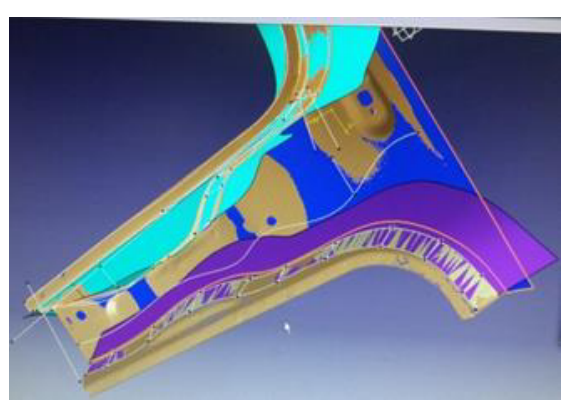

Fig. 5. Surfacing of the B-pillar part.

The surfaces were created with the points, lines, and finally with the command of multi-section surface. The created surfaces were then extended with the extend command under the "Freestyle", workbench. After creating and extending the surfaces, with the help of trim and sprit operation, the final surfaces according to the mesh were constructed as showed in figure 6 . 


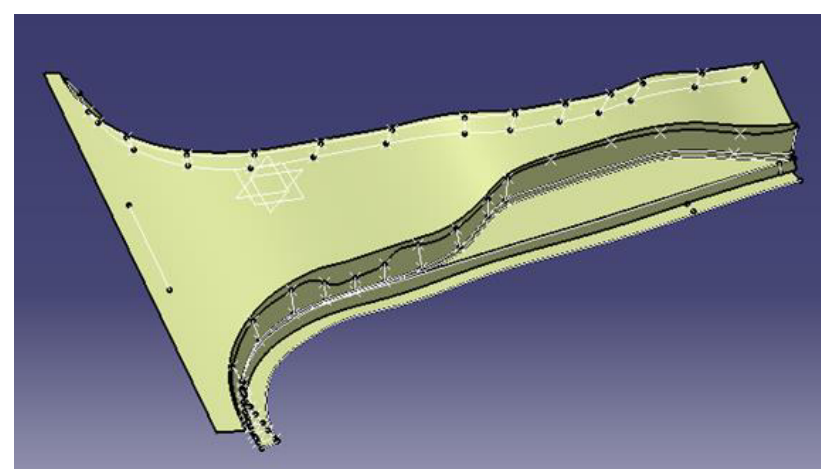

Fig. 6. Created surfaces and excess cut away.

After creating all the surfaces, the join commend was employed located under the "Generation Shape Design" work bench that combined all the surfaces into a single one which then provided the opportunity to create the solid part of the B-pillar. Thick surface command allowed in creating the solid CAD body from the combined surfaces. For the case of the existing B-pillar, the thickness was assigned to $1.2 \mathrm{~mm}$ according to the physical geometry. Fig 7 shows the solid form of the reverse engineered B-pillar part. This concluded the reverse engineering of the existing B-pillar part. In the next section, procedures for developing B-pillar part with non-uniform sections were introduced.

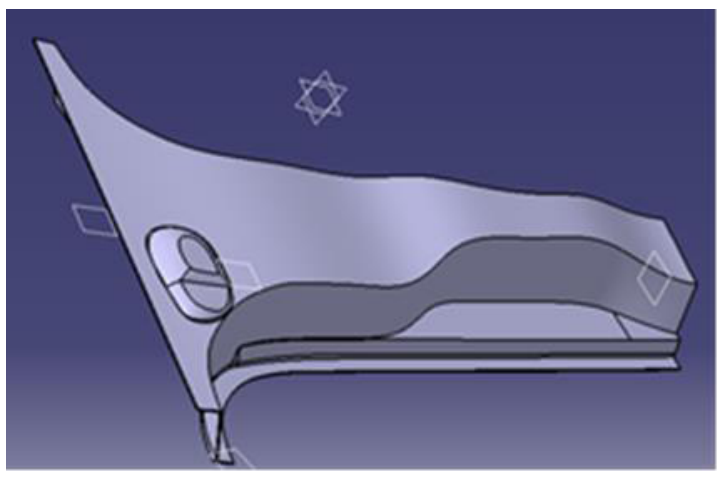

Fig. 7. B-pillar part in solid form after surface thicken command in CATIA V5.

\subsection{CAD model development of non-uniform thickness B-pillar part}

In this section, reverse engineered B-pillar part of the existing design went for further CAD modelling by CATIA V5 to have non-uniform thickness sections of the B-pillar. The previous design shown in figure 5 was divided into five different sections to allocate the variable thicknesses. The adjacent surfaces were given fillet as it had sharp edges, and a reference plane has been set at the top of the part. Fillet and plane operation was done under the "'Generation Shape Design'" workbench. The new planes were set to around $90 \mathrm{~mm}$ apart. After creating the planes, a new geometrical set for each of the sections were developed by split command using "Generative Shape Design" workbench. Then using "Part Design"' workbench, the surfaces were thicken to $1.2 \mathrm{~mm}, 1.6 \mathrm{~mm}, 2.2 \mathrm{~mm}, 1.4 \mathrm{~mm}$ and $1 \mathrm{~mm}$ respectively as shown in the figure 8 . The primary intention was to introduce the thicknesses according to the research conducted by [11], however, at the very last section at the bottom it was limited to $1 \mathrm{~mm}$ rather than $1.2 \mathrm{~mm}$. This occurred due to having a curved shaped socket present in the existing design of the B-pillar. Later on this will be overcome 
by thickness optimization using finite element analysis. With current facility at the forging laboratory, Universiti Sains Malaysia; work piece with a dimensional length of maximum $900 \mathrm{~mm}$ is possible to operate. So the CAD modelling here in this research was taken the total length of the part as approximately $500 \mathrm{~mm}$ to avoid unavoidable error.

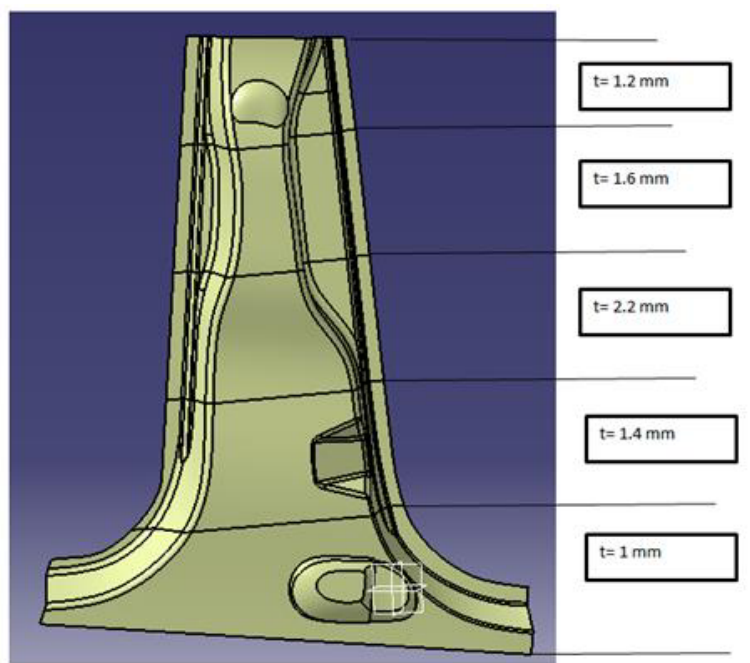

Fig. 8. Initial partition and thickness of the B-pillar part.

After providing all the necessary input for the surface thicken command, the B-pillar part was constructed as one solid body with different thicknesses across its sections. In the surface thicken command under "Part design" workbench, it was employed the second offset thickness that created the non-uniform thickness from the bottom side. These were the processes that how the surfaces of the B-pillar part became solid form from surfacing. Figure 9 shows both the front and back side of the experimental B-pillar with non-uniform sections in its solid form. In addition, figure 10 shows the section transitions with a zoom in view of the B-pillar part.

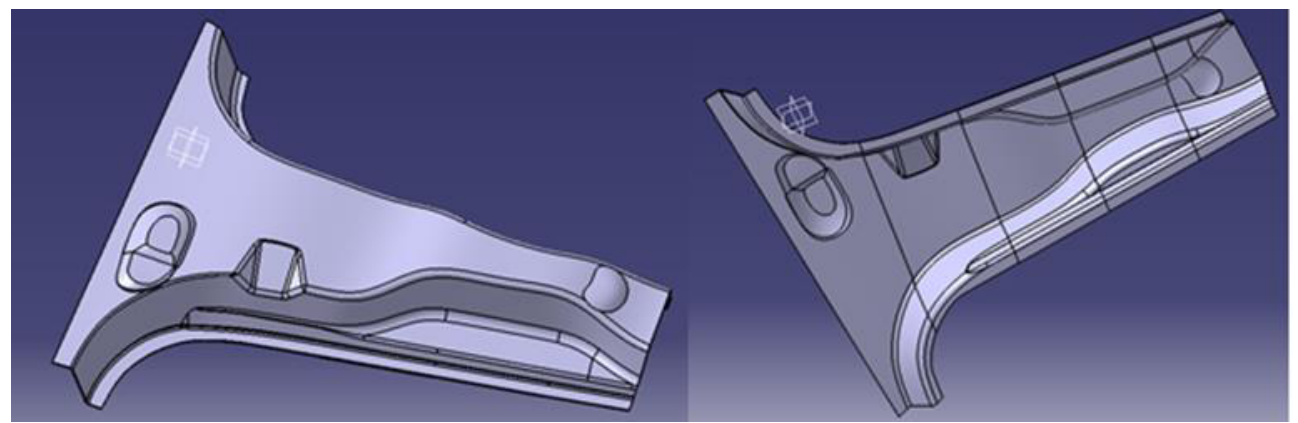

Fig. 9. Experimental B-pillar part with non-uniform sections in solid form. 


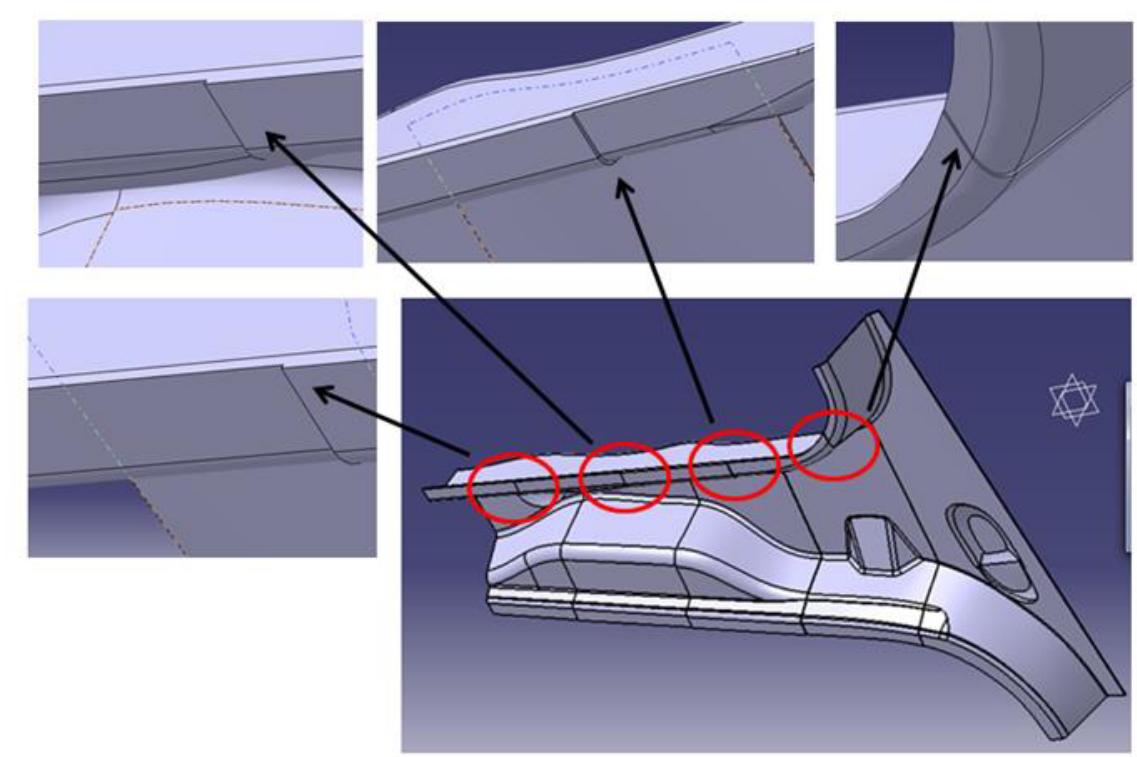

Fig. 10. Thickness transition sections of non-uniform sections of B-pillar part.

\section{Conclusions}

This paper described the procedure of RE operation of a complex automotive BiW component, B-pillar where an existing B-pillar part was reverse engineered with help of a 3D optical scanner and CATIA V5 as CAD application software. Subsequently, five different thicknesses across the B-pillar part were introduced in the final design to have non-uniform thickness B-pillar part. Due to existing facility at the forging lab of Universiti Sains Malaysia; where a 100 ton forging machine can only allow the part to be maximum of $900 \mathrm{~mm}$ in length, inhibits as major limitation of conducting RE of the B-pillar which was $1500 \mathrm{~mm}$ in total length. To have necessary allowance and tolerance for tooling design and for smooth machine operation, the RE of the existing B-pillar was limited to $500 \mathrm{~mm}$, so that future cold forging operation can be performed. In future research mold tooling design will be developed so that the part designed in this current research can be utilized for cold forming process where the final B-pillar will have non-uniform thickness. Furthermore, research will be carried out to optimize the thickness for different sections of the B-pillar part using finite element method (FEM) that can provide optimum thickness distribution providing weight reduction opportunity.

The authors want to acknowledge Ministry of Higher Education for their sponsorship through Fundamental Research Grant Scheme (Acc. No. 203/PMEKANIK/6071308)

\section{References}

1. H.-H. Bok, M.-G. Lee, E. J. Pavlina, F. Barlat, and H.-D. Kim. International Journal of Mechanical Sciences, 53(9): p. 744-752.(2011)

2. F. Pan, P. Zhu, and Y. Zhang. Computers \& Structures, 88(1-2): p. 36-44.(2010)

3. N. P. Lutsey. Institute of Transportation Studies.(2010)

4. R. Pathare and M. Mansour SAE Technical Paper SAE (2009) 
5. G. Sun, F. Xu, G. Li, and Q. Li. International Journal of Impact Engineering, 64: p. 62-74.(2014)

6. M. F. Adnan, A. B. Abdullah, and Z. Samad. The International Journal of Advanced Manufacturing Technology: p. 1-12.(2016)

7. P. O. Marklund and L. Nilsson. Structural and Multidisciplinary Optimization, 21(5): p. 383-392.(2001)

8. P. Weissler. Focus B-pillar 'tailor rolled' to 8 different thicknesses. Available from: http://articles.sae.org/7695/. (2010)

9. K. Bandyopadhyay, S. Basak, S. Panda, and P. Saha. Materials \& Design, 67: p. 558570.(2015)

10. M. Hyrcza-Michalska, J. Rojek, and O. Fruitos. Archives of Civil and Mechanical Engineering, 10(4): p. 31-44.(2010)

11. M. Pfestorf. The mixed Material Concept of the new BMW X5. Available from: http://www.autosteel.org/ /media/Files/Autosteel/Great\%20Designs\%20in\%20Steel/G DIS\%202007/04\%20-

\%20The $\% 20$ Mixed $\% 20$ Material $\% 20$ Concept $\% 20$ of $\% 20$ the $\% 20$ New $\% 20 B M W \% 20 X 5$ .pdf. (2007)

12. M. Merklein, M. Johannes, M. Lechner, and A. Kuppert. Journal of Materials Processing Technology, 214(2): p. 151-164.(2014)

13. Y. Chen and C. Ng. Computers \& Industrial Engineering, 33(3): p. 481-484.(1997)

14. E. Bagci. Advances in Engineering Software, 40(6): p. 407-418.(2009)

15. M. Paulic, T. Irgolic, J. Balic, F. Cus, A. Cupar, T. Brajlih, and I. Drstvensek. Procedia Engineering, 69: p. 795-803.(2014) 